\title{
RECENT RESULTS OF THE FIREBIRD MISSION
}

\author{
E. Lorenz ${ }^{1}$, W. Halle ${ }^{1}$, Ch. Fischer ${ }^{1}$, N. Mettig ${ }^{1}$, D. Klein ${ }^{2}$ \\ ${ }^{1}$ German Aerospace Center DLR Institute of Optical Sensor Systems, D-12489 Berlin, Rutherfordstraße 2 \\ ${ }^{2}$ German Aerospace Center (DLR,, Earth Observation Center (EOC), D-82234 Wessling, Oberpfaffenhofen \\ eckehard.loren@dlr.de, winfried.halle@dlr.de, c.fischer@dlr.de, nora.mettig@dlr.de,doris.klein@dlr.de
}

\section{Future Missions}

KEY WORDS: Small Satellite Constellation, Infrared Instruments, High Temperature Events, Advanced On Board Processing

\begin{abstract}
:
Two years ago the German Aerospace Center (DLR) reported on the ISRSE36 in Berlin about the FireBird Mission (Lorenz, 2015). FireBird is a constellation of two small satellites equipped with a unique Bi- Spectral Infrared Instrument. Whereas this instrumentation is mainly dedicated to the investigation of high temperature events a much wider application field was meanwhile examined. The first of these satellites- TET-1 - was launched on July $22^{\text {nd }} 2012$. On the ISRSE36 could be presented the results of two years of operation. The second satellite- BIROS- was launched on June $22^{\text {nd }} 2016$. The outstanding feature of the Infrared Instruments is their higher ground sampling resolution and dynamic range compared to systems such as MODIS. This allows the detection of smaller fire events and improves the quality of the quantitative analysis. The detailed analysis of the large number of data sets acquired by TET in the last two years caused significant methodically improvements in the data processing. Whereas BIROS has the same instrumentation as TET a number of additional technological features implemented in the satellite bus expand the application field of the instruments remarkably. New High-Torque-Wheels will allow new scanning modes and generating with this new data products to be discussed. A Giga Bit Laser downlink terminal will enable near real time downlinks of large data volumes reducing the response time to disaster events. With an advanced on board processing unit, it is possible to reduce the data stream to a dedicated list of desired parameters to be sent to users by an OrbCom modem. This technology can serve such Online Information Portals like the Advanced Fire Information System (AFIS) in South Africa. The paper will focus on these new items of the FireBird mission.
\end{abstract}

\section{INTRODUCTION}

FireBird is defined as a constellation of two small satellites mainly dedicated to the investigation of high temperature events. The first satellite TET-1 was launched on $22^{\text {nd }}$ July 2012. The second satellite- BIROS- was launched on $22^{\text {nd }}$ June 2016. The outstanding feature of the infrared instruments is their higher ground sample resolution and dynamic range compared to systems such as MODIS as shown in Table 1 and Figure 1.

The comparison with infrared instruments on other satellites will be completed with details of the spectral band design as shown in Figure 2.

\section{MISSION DESIGN}

Both satellites are flying in a constellation to improve the coverage of the areas of interest. In Figure 3 is shown an example. On the left side is shown the MWIR Image and the planned data take swath for TET at 26. 01. 2017 06:37 UTC (night time), on the right side is shown the MWIR Image and the planned data take swath for BIROS at 28. 01. 2017 13:50 UTC (day time). The images are difficult to compare because of the different time of day and the different contrast due to the huge fire events at $26^{\text {th }}$ January. But it demonstrates the opportunity of the constellation covering the same area within of two days because they have different orbital nodes.

\subsection{Operation}

In Figure 4 is shown the general FireBird Operation Schema. The satellites are operated by the German Operation Center GSOC with support of the Institute of Optical Sensor Systems in Berlin where the satellites were designed.

\begin{tabular}{|l|l|l|}
\hline Wave length & $\begin{array}{c}\text { 3 line-Camera } \\
\text { (3 line FPA) }\end{array}$ & \multicolumn{1}{|c|}{ 2 Infrared- Cameras } \\
$\begin{array}{l}460-560 \mathrm{~nm} \\
565-725 \mathrm{~nm} \\
790-930 \mathrm{~nm}\end{array}$ & $\begin{array}{l}\text { MWIR: } 3,4-4,2 \mu \mathrm{m} \\
\text { LWIR: 8,5-9,3 } \mu \mathrm{m}\end{array}$ \\
\hline Focal length & $90,9 \mathrm{~mm}$ & $46,39 \mathrm{~mm}$ \\
\hline FOV & $19,6^{\circ}$ & $19^{\circ}$ \\
\hline F-Number & 3,8 & 2,0 \\
\hline Detector & CCD- Zeile & CdHgTe Arrays \\
\hline Detector cooling & Passive, $20^{\circ} \mathrm{C}$ & Stirling, $80-100 \mathrm{~K}$ \\
\hline Pixel size & $7 \mu \mathrm{m} \times 7 \mu \mathrm{m}$ & $30 \mu \mathrm{m} \times 30 \mu \mathrm{m}$ \\
\hline Number of Pixel & $3 \times 5164$ & $2 \times 512 \mathrm{staggered}$ \\
\hline Quantization & $14 \mathrm{bit}$ & $14 \mathrm{bit}$ \\
\hline Ground Resolution & $42,4 \mathrm{~m}$ & $356 \mathrm{~m}$ \\
\hline GSD & $42,4 \mathrm{~m}$ & $178 \mathrm{~m}$ \\
\hline Swath width & $211 \mathrm{~km} \mathrm{~km}$ & $178 \mathrm{~km}$ \\
\hline Data rate & max $44 \mathrm{MBit} /$ & $0,35 \mathrm{MBit} / \mathrm{s}$ \\
\hline Accuracy & $100 \mathrm{~m}$ on ground & $100 \mathrm{~m}$ on ground \\
\hline
\end{tabular}

Table 1 Main FireBird camera parameters 
The commanding and the control of the satellites will be executed via the antennas in Weilheim. The receipt and the archiving of the scientific data will be realised in the German Data Center in Neustrelitz. Other DLR ground stations will be included on demand.

Nevertheless the DLR ground station net is not sufficient to compensate the disadvantage of the $\mathrm{S}$ Band downlink. Therefore additional receiving opportunities are desirable, e.g. South Africa and in Brasilia.

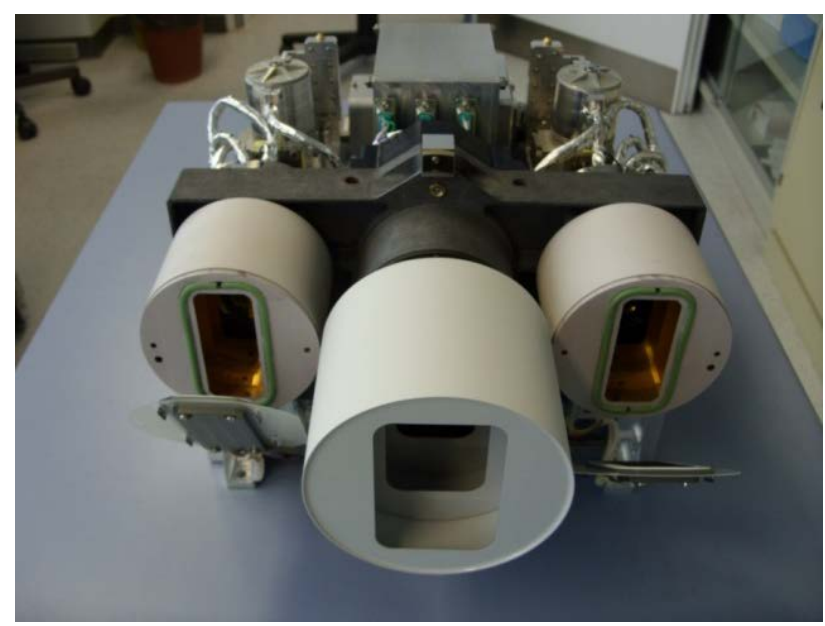

Figure 1 FireBird camera

comple

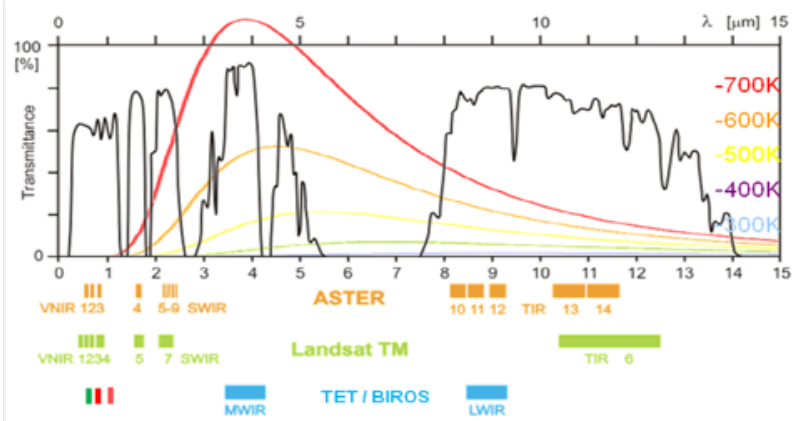

Figure 2 spectral Design of the FireBird instruments

\subsection{The BIROS Satellite}

The main payload as described in the introduction is the same for both satellites. Additional to this the BIROS satellite is equipped with various technological experiments which can contribute in case of a successfully testing to a remarkably improvement of the mission design (Halle, 2014).

2.2.1 Propulsion Technology: A new High Torque Wheel for a high agility was developed and accommodated in BIROS payload compartment together with a cold-gas propulsion system. The High Torque Wheel will allow very rapid pointing manoeuvres to expand the swath or to perform stereo recordings. The cold-gas propulsion system was mainly used to demonstrate formation flying manoeuvres with the Pico Sat which was launched in orbit from BIROS.
2.2.2 The Pico Sat Launcher: A Pico Sat launching Unit was accommodated on BIROS for separation of BEESAT-4 of the Technical University Berlin. BEESAT-4 is equipped with a GPS receiver and a Satellite Interlink transmitting the GPS data to BIROS. With this combination could be collected a lot of data regarding a constellation fly with several satellites.

2.2.3 The OSIRIS experiment: OSIRIS (OSIRIS (Optical Space Infrared Downlink System) is a new onboard optical communication terminal, developed at DLR. Three different laser systems for downlink communications will achieve data rates up to $1 \mathrm{Gbit} / \mathrm{s}$. A beacon laser in uplink will support the BIROS attitude control. It may also be used for an optical uplink.

2.2.4 The OrbComm Modem: BIROS contains a technical experiment using a hardware VHF modem allowing the communication with an ORBCOMM satellite. Via this modem it will be possible to inform directly the ground users via email and SMS about an on-board detected hot-spot with the concerning geo-location as described in (Briess, 2003).

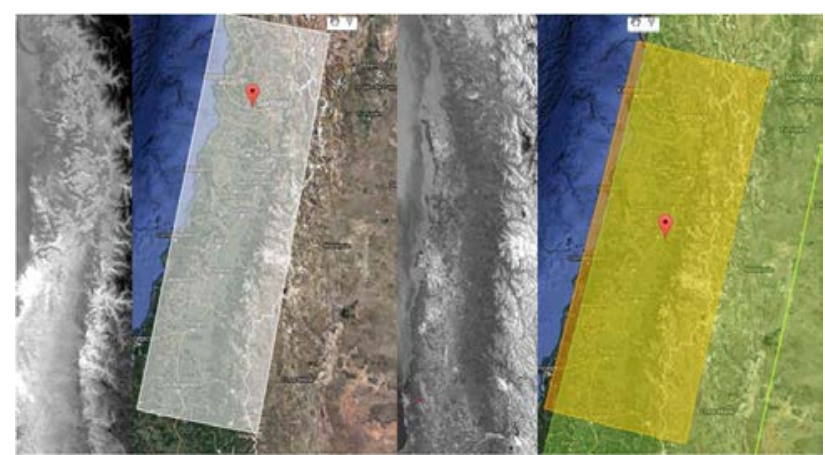

Figure 3 MWIR Image and planned Swath of TET-1(left) and BIROS (right)

\subsection{Data acquisition}

The data take planning process will be supported by the planning tool SPOT (Figure 4) developed by DLR GSOC (German Space Operation Center). Based on the actual TLE the SPOT tool gives an overview of the satellite orbits at any day.

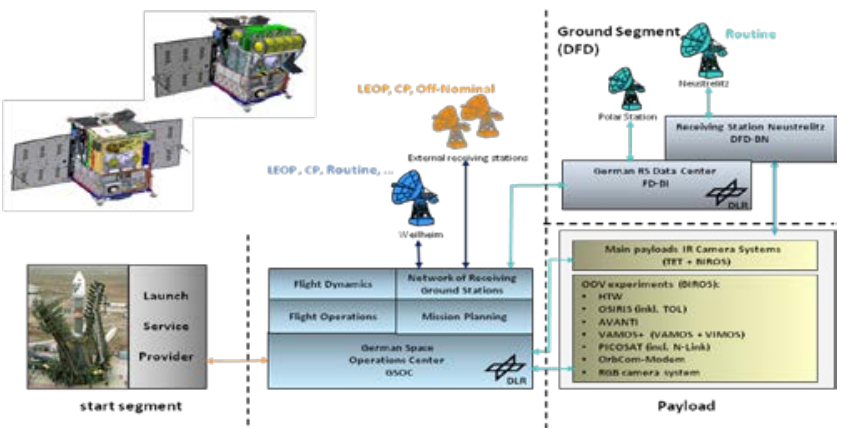

Figure 4 General FireBird Operation Schema

With this it is very easy to get an overview of the possible targets covered by the orbits. It is also possible to select certain targets and ask for all possible data takes within a selected period. 
Collecting all incoming planning requests SPOT is managing the necessary recourses like the thermal and the power regime, the available mass memory on board (400 MB) and the available ground stations (currently Neustrelitz in Germany and a polar station). Based on this recourse management it is possible to acquire up to 10 data takes per day.

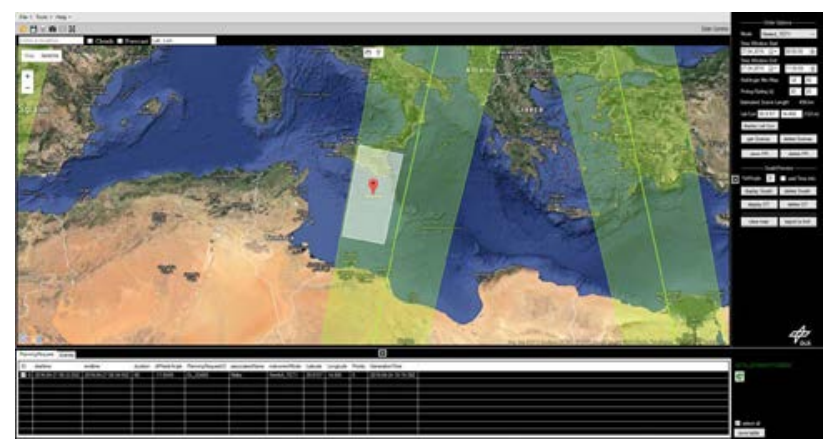

Figure 5 GUI of the data take planning tool SPOT

The user can choose one of four standard instrument configurations which were mainly establish to save on board memory capacity and to minimise the downlink data volume. During the night vision measurements (Fire Night) the visual bands will be switched off. At day the GSD of the visual bands can be switched between $40 \mathrm{~m}$ and $160 \mathrm{~m}$ and it can be selected which of the visual bands should be used and transmitted to Earth. In the consequence this is a decision between the GSD and the area to be monitored.

\subsection{Data processing and Data Products}

The down linked data sets will be collected, sorted and archived in the DLR DFD ground station in Neustrelitz. There is also implemented the Ground Processing Unit generating the FireBird data products.

The level 0 dataset includes -depending on the selected operation mode- up to five measurement files, two calibration files for the infrared cameras and an attitude file.

Based on these raw data files the L1b standard products will be generated. L1b products are radiometric calibrated radiances on top of atmosphere with geographic annotation and related Meta Data Information. This information can be delivered in an ENVI conform format with additional XML files or in a HDFEOS-5 format.

The L1b standard products are the base for the higher L2 data products. Currently is implemented only the Bi Spectral method for the analysis of High Temperature Events (HTE) as a L2 data product. Other methods like Sea Surface Temperature (SST) are planned.

Valid products will be registered in the DLR EOWEB Catalogue (see Figure 6). Here registered user can search for products of interest and in case of success place orders for level $1 \mathrm{~b}$ products. These products will be reprocessed from the archived L0 products.

\section{RECENT RESULTS}

Since 2013, TET-1 acquired approximately 4700 data takes. Two years ago DLR reported on the ISRSE36 in Berlin about the FireBird Mission and the results. The main topic was of course the HTE.

\subsection{High Temperature Events}

Several quite catastrophic fire events occurred in the last two years.

3.1.1 Kalimantan: On the ISRSE36 were shown the images of huge peat fires in October 2014 caused by the El Ninio phenomenon. One year later we had to record much stronger events as shown in Figure 7.

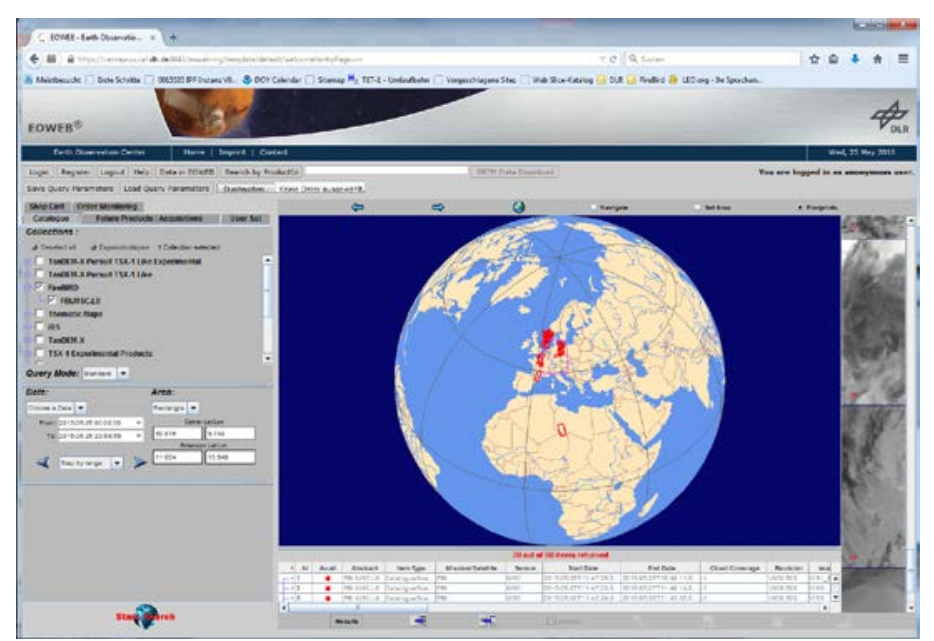

Figure 6 GUI of the DLR EOWEB Catalogue

In the comparison with MODIS is clearly seen the trade-off between ground resolution and swath width. Moreover the TET-1 spectral bands demonstrate a better penetration through the smoke layers. The reason has to be investigated in detail.

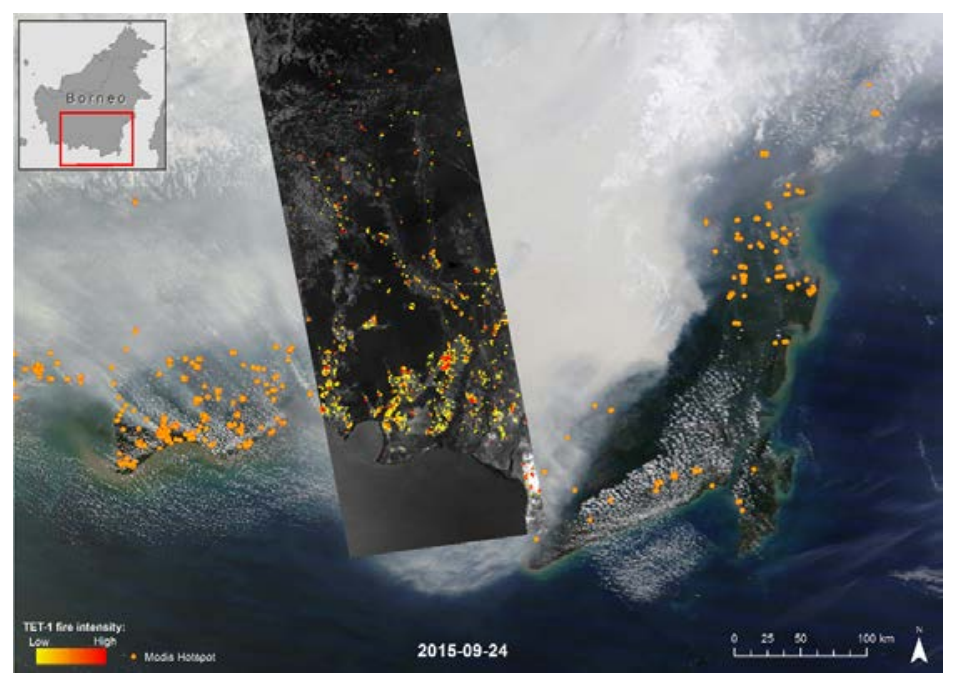

Figure 7 TET imagery with detected fires in Kalimantan superimposed on MODIS from 24 September 2015 (CRSS)

3.1.2 Portugal: Figure 8 shows the development of the fire events in Portugal in the period 11.-14. August 2016. MODIS data serve hereby as a map back up. 
3.1.3 Israel: In November 2016 wildfires started in Israel and spread rapidly over the country on the following days. On November 25 at 11:25 UTC, DLR's TET-1 satellite captured major hot spots in the region (Figure 9).
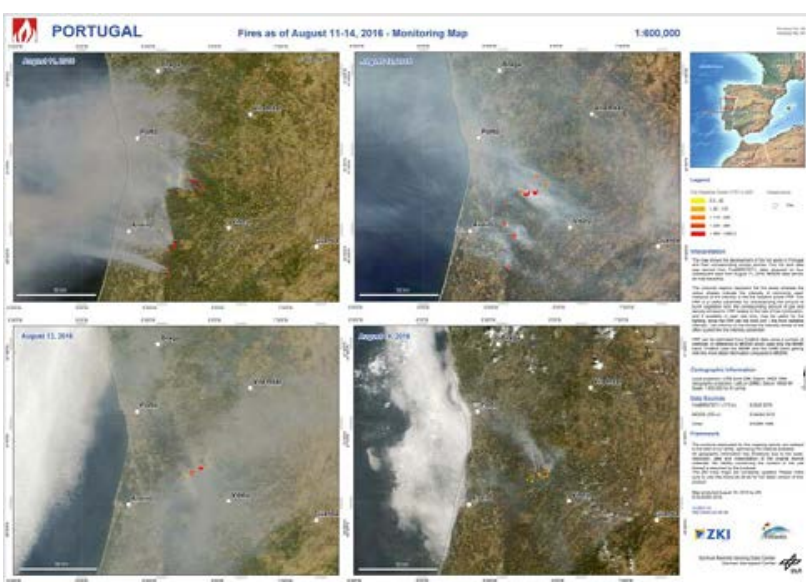

Figure 8 Fires in Portugal 11.-14. August 2016 (@ DLR ZKI)
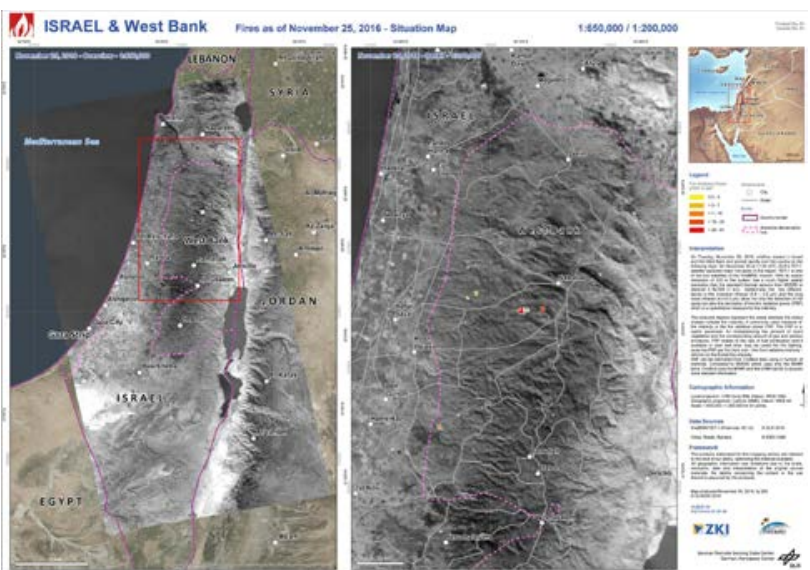

Figure 9 Fires in Israel 25. November 2016 (@ DLR ZKI)

3.1.4 Chile: On January 24, 2017, the International Charter 'Space and Major Disasters' was activated for forest fires in Chile. The DLR/ZKI is responsible for the Project Management of this Charter Call and supports the 'Chilean National Office of Emergency of the Interior Ministry' (ONEMI) of Chile with the provision of satellite data and value added disaster information products. Figure 10 is based on a TET- 1 data take at January 26, 2017.

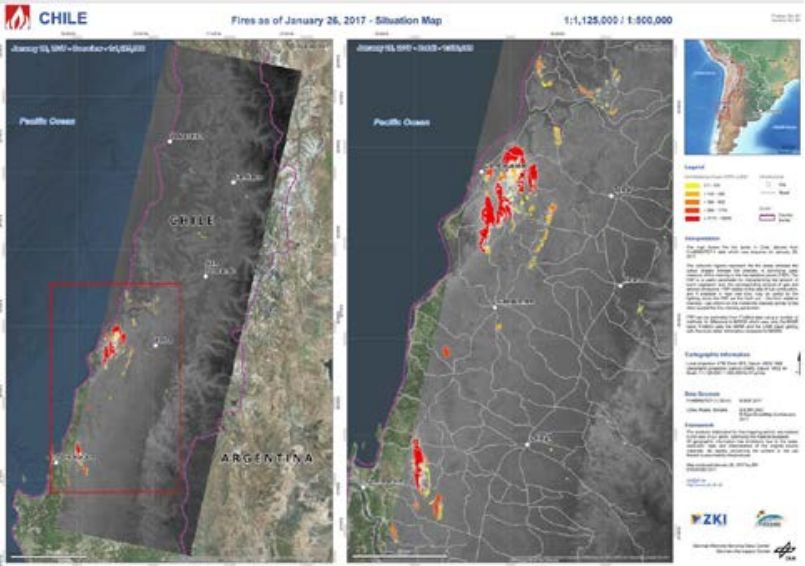

Figure 10 Fires in Chile 26. January 2017 (C DLR ZKI)

3.1.5 BIROS HTE Products: As shown in Figure 3 BIROS was also applied to the fire observation in Chile. But currently the BIROS instrumentation is up to now in the commissioning phase and is less operational. Further more for the day time images in January were not added the visible band and so it was not possible to generate a L2 product. Meanwhile these restrictions are overcome. In Figure 11 is shown the BIROS L2 product of a data take over Qatar at 20.April 2017 and the comparison with the related VIIRS product.

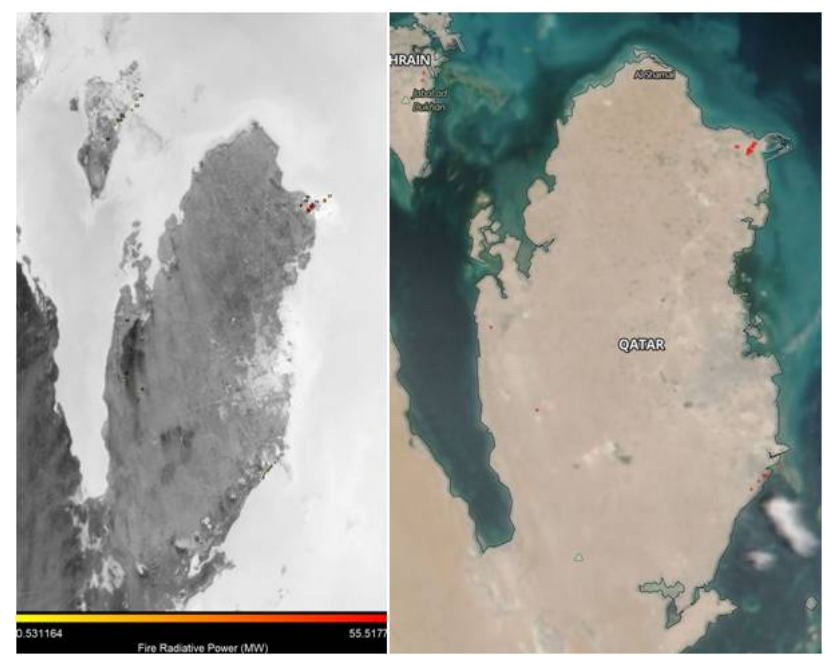

Figure 11 BIROS L2 Product of Gas flares in Qatar (left) and comparison with a related VIIRS product

\subsection{Sea Surface Temperature}

The application of good infrared instrumentation can't be restricted only one application field. Therefore were made several studies related to normal and lower environmental temperatures. Very good results were achieved by a study dedicated to the Sea Surface Temperature. The methodical approach and the result are depicted in Figure 12 (Mettig, 2016). 


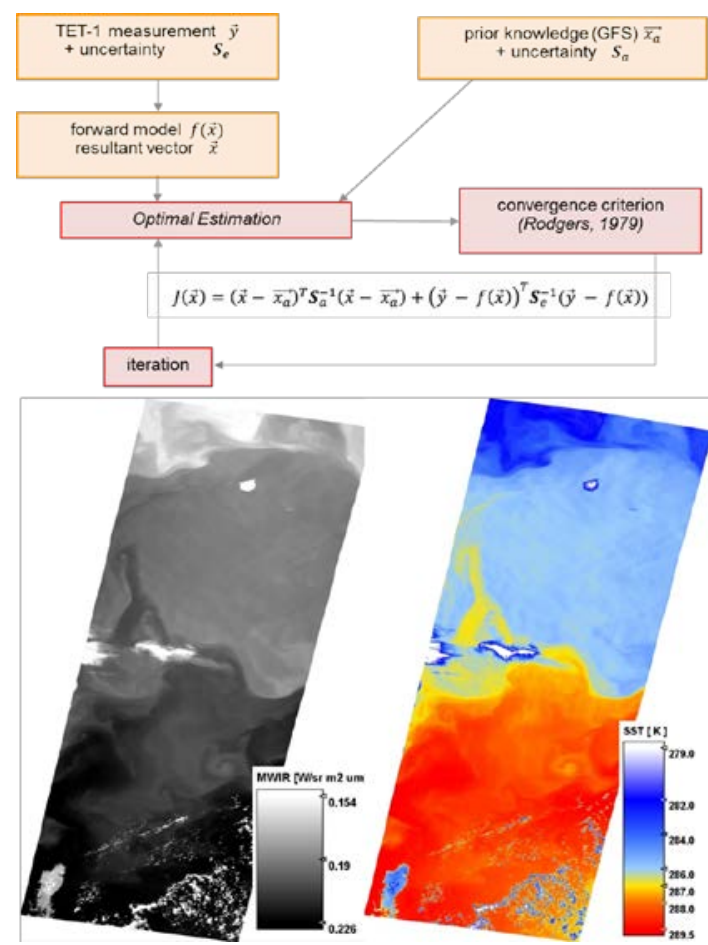

Figure 12 Method and Result of the SST Study

\section{FIREBIRD PRODUCT VALIDATION}

In the previous section were shown some examples comparing the FireBird results with related results of other EO missions. All of them have a more qualitative character. In a next step some quantitative results are required.

\subsection{South Africa Experiment 2014}

About this international validation experiment was reported in the contribution to the ISRSE36. Therefore we will point to the (Govender, 2014) which was issued after the conference. More experiments would be desirable, but concrete plans are not known.

\subsection{Fire Detection Campaign with VIIRS}

In October 2015 was agreed within a NASA project a joint validation campaign of TET-1 and VIIRS. Out of different organisational reasons the campaign could be realised only in October havening only one joint data take- but the conformity of the results is convincing.

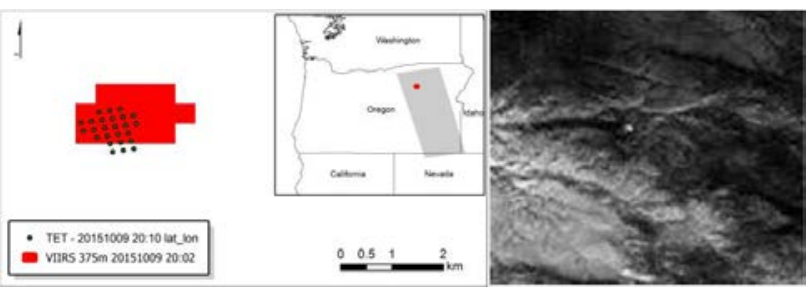

Figure 13 Results of the campaign TET-1 (right) with VIIRS (analysis left)

\subsection{Comparison with MODIS}

The benchmark in the Earth Observation is of course MODIS Thus a comparison of the FireBird products with related products of MODIS is mandatory. But here is to consider that the Fire Radiative Power products of MODIS are different from FireBird. Whereas MODIS uses the Wooster Method (Wooster, 2003) which is based only on the MWIR band FireBird uses the Bi Spectral Method (Dozier, 1981 and Oertel, 2005). Different results can be expected. In Figure 14 is shown a related result.

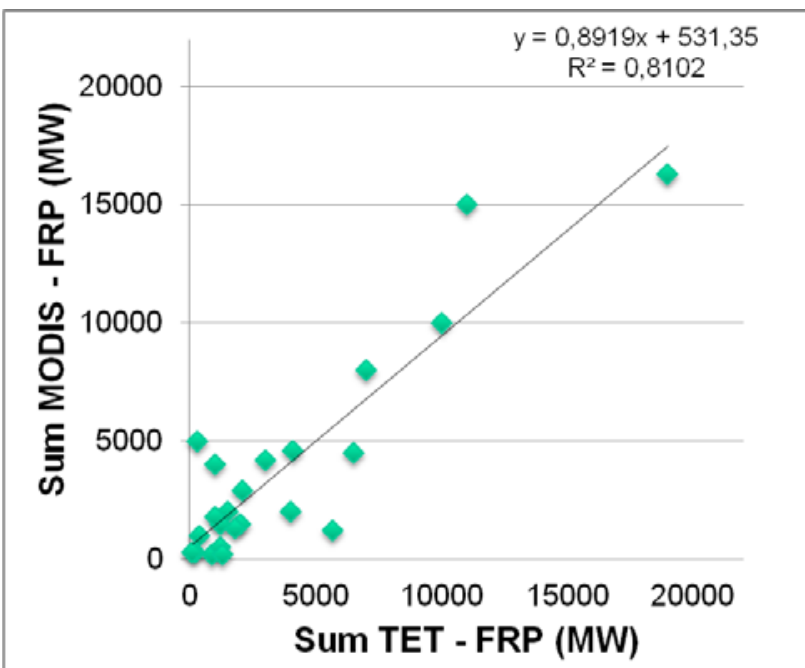

Figure 14 Comparison of TET and MODIS within of 20 scenes where the time difference is not higher than $3 \mathrm{~h}$

The linear dependence of $\sim 0.9$ results in a correlation coefficient of $\sim 0.81$. The offset of 531 has to be discussed.

\subsection{The Lascar validation campaign}

To get a statistical acceptable material for a ground based validation campaign were provided in 2016 about 75 data takes over the Lascar region. The Lascar region has all elements to validate all aspects of the FireBird data products. All objects in the region are well known in their characteristics- the radiometric as well the geometric. The Lascar itself is a relatively stable HTE source- in difference to other HTE sources like gas flares.

4.4.1 A new HTE detection approach: In the Lascar region will be visible a problem of the traditional detection procedure used also by FireBird. In presence of many cold clouds the detection probability of small HTE dramatically decreases. To overcome this disadvantage a new approach will be investigated. Instead of the empirical threshold hierarchy used up to now it will be introduced quantitative criteria based on the histogram analysis. We will give here only a short draft; details will follow in a later publication.

Combining the normal infrared radiation model with this of the Bi Spectral Method we get that every HTE will offer according to (1) an effective emissivity greater 1 .

$\varepsilon_{\mathrm{i}}^{\mathrm{m}}=\varepsilon_{\mathrm{i}} *\left(a\left(\frac{B\left(T_{F^{x}} \lambda_{\mathrm{i}}\right)}{B\left(T_{B^{x}} \lambda_{\mathrm{i}}\right)}-1\right)+1\right)$

a - area of the HTE as percentage of a pixel

$\mathrm{T}_{\mathrm{F}}$ and $\mathrm{T}_{\mathrm{B}}$ - The HTE and the background temperature

$\lambda \mathrm{i}-$ wavelength with $\mathrm{i}=\mathrm{LWIR}$ or MWIR

$\varepsilon$ - the real or effective emissivity 
In terms of a histogram this means that there should be between 1 and the effective emissivity some empty classes. This will be a strong detection criterion which works very well.

Unfortunately it is not possible to calculate the emissivity for each spectral band separately. But it is possible to calculate the proportion of the emissivity of both infrared bands and this works also as a strong detection criterion.

In Figure 15 is demonstrated the difference of the MWIR radiance histogram (MWIR radiance image is used in the traditional detection method as the main image) and the emissivity proportion histogram which is the new main image for the detection. It is definitely a sharper differentiation of the HTE in the emissivity proportion histogram and with this a higher probability of the HTE detection.

With this approach the entire Bi Spectral analysis procedure has to be revised.

4.4.2 Multi Resolution Approach: The usage of the emissivity proportion instead of the MWIR radiance as the main data source has also a completely other aspect. At day time it is necessary to consider the reflection of the sun light. For this part will be used at least one visible band. In Table 1 is shown that the visible bands have a GSD of $40 \mathrm{~m}$. The traditional approach uses a down scaling of the visible band GSD to $160 \mathrm{~m}$. This is necessary to generate comparable threshold criteria for the analyses on the base of the radiance images.

Using the emissivity proportion method which includes in the same formulas in a consistent form also the visible bands it is also possible to use a consequent up scaling to the GSD $40 \mathrm{~m}$. With this the $40 \mathrm{~m}$ resolution of the visible bands will be delegated to the emissivity proportion image as demonstrated by Figure 16 .

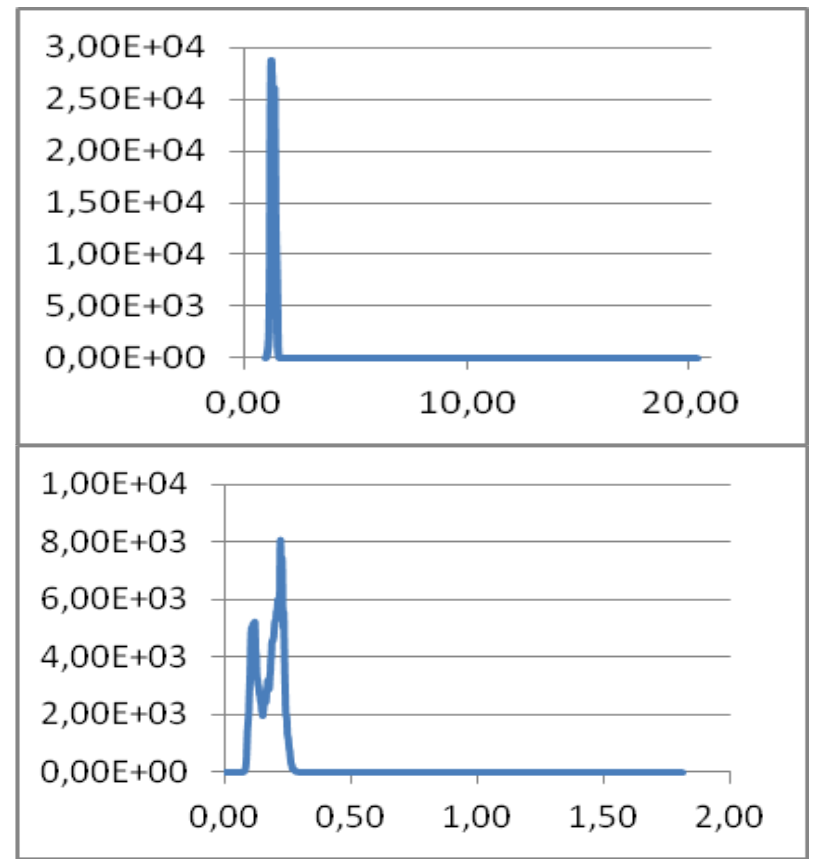

Figure 15 Histograms of the emissivity proportion (upper) and the MWIR radiance image (lower)

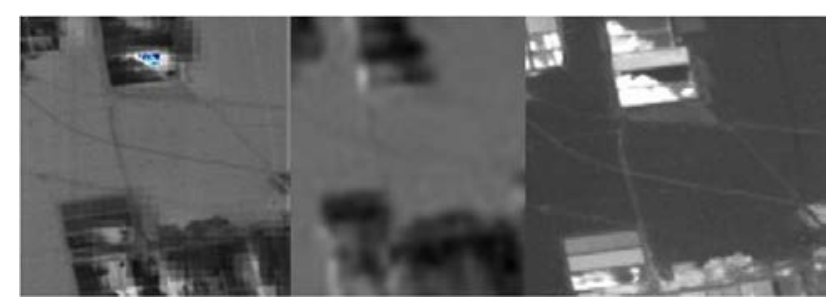

Figure 16 Calculation of emissivity proportion using GSD 40m (left) and 160m (mid) and the VisRed detail with GSD 40m (right)

\section{CONCLUSIONS}

In this paper were demonstrated the capabilities of small satellites to detect and monitor high temperature events. Small satellites can be an alternative to the established, bigger satellites if they will be operated in an adapted mode. With the launch of BIROS in 2016 FireBird is a constellation of two small satellites. First results demonstrate the remarkably potential of a small satellite constellation.

\section{REFERENCES}

Briess, K., Jahn, H., Lorenz, E., Oertel, D., Skrbek, W., \& Zhukov, B. (2003). Fire recognition potential of the Bi-spectral InfraRed Detection (BIRD) satellite. Int. J. Remote Sensing, 24, 865-872.

Dozier, J.(1981). A method for satellite identification of surface temperature fields of subpixel resolution. Remote Sens. Environm., 11, 221-229.

Govender, N (2014). KNP Field Validation Campaign Report - 17th -31st August 2014

Compiled by Navashni Govender with contributions from Wilfrid Schroeder, Louis Giglio, Bob Kremans, Gernot Ruecker, Olaf Frauenbergen, Martin Wooster, Mark Dejong, Bruce Main, Ronan Paugam, Evan Ellicott and Anja Hoffmann

Halle, W., Bärwald, W., Raschke C., Terzibaschian T. (2014) The DLR -Satellite BIROS in the FireBIRD Mission 4S Symposium 26 May 2014 - Friday, 30 May 2014, Porto Petro, Majorca, Spain

Lorenz, E. (2013). Thermal Remote Sensing with Small Satellites: BIRD, TET and Next Generation BIROS

In

Thermal Infrared Remote Sensing

Springer Dordrecht Heidelberg New York London 2013

Editors C. Kuenzer \& St. Dech

Lorenz E. , Mitchell S., Säuberlich T., Paproth C., Halle W. , O. Frauenberger (2015). Remote Sensing Of High Temperature Events By The Firebird Mission Symposium on Remote Sensing of Environment (ISRSE), Berlin 11.-15. May 2015. Paper No. ISRSE36-101

Mettig N. (2016). Sensitivitätsstudie zur Bestimmung der Meeresoberflächentemperatur aus Messungen des Satelliten TET-1. Masterarbeit, Deutsches Zentrum für Luft- und Raumfahrt 
Oertel, D (2005). ECOFIRE Study on Scientific Assessment of Space-borne High Temperature Event Observing

Mission Concepts

ESTEC Contract No. 17690/03/NL/FF

Final Report, December 2005

Wooster, M., Zhukov, B., \& Oertel, D. (2003). Fire radiative energy release for quantitative study of biomass burning: derivation from the BIRD experimental satellite and comparison to MODIS fire products. Remote Sens. Environm., 86, 83107.

Zhukov, B., E. Lorenz, D. Oertel, M. Wooster and G. Roberts Experience of detection and quantitative characterization of fires during the experimental small satellite mission BIRD

Final Report to the BIRD Mission, DLR 2005 